Res Pública Revista de Historia de las Ideas Políticas

ISSN: $1131-558 \mathrm{X}$

http://dx.doi.org/10.5209/rpub.72081

\title{
Miradas sobre Latinoamérica: crítica, política y cultura
}

\author{
Cristina Catalina*
}

Cómo citar: Catalina, C. (2021). Miradas sobre Latinoamérica: crítica, política y cultura. Res Pública. Revista de Historia de las Ideas Políticas, 24(1), 1-2.

La reflexión sobre las diferentes realidades contemporáneas y pasadas de Latinoamérica es tan diversa como su objeto. No se agota en una mirada teórica unívoca, ni se pliega a un relato unitario. En este sentido, el número que aquí presentamos pretende proseguir con y contribuir a la tarea incesante y múltiple de ofrecer nuevas perspectivas sobre el pensamiento latinoamericano, así como sobre sus distintas realidades, en aquello que las comprende como latinoamericanas. En efecto, el número "Miradas sobre Latinoamérica: crítica, política y cultura" ofrece una mirada interdisciplinar -desde la filosofía, la crítica literaria, la historia o los estudios culturales- a realidades plurales e interconectadas, como son las literaritas, las sociopolíticas o las culturales.

El número se abre con un artículo de Jorge Álvarez Yágüez en el que se abordan críticamente algunos de los fundamentos del pensamiento decolonial. "La crítica de la modernidad en el pensamiento decolonial" el analiza la conceptualización que la teoría decolonial hace de la modernidad y la cultura, desde una particular categorización de la geopolítica del saber. El artículo muestra cómo el pensamiento decolonial apuntala su crítica en un concepto de cultura reduccionista, en la medida en que ésta se identifica con un ámbito separado, hegemónico y delimitado, que además de implicar una culturalización de la política y lo social, no habría superado los límites del concepto de cultura de matriz germánica y moderna. Con ello, Álvarez Yágüez trata de mostrar que el pensamiento decolonial establece un injusto tipo vínculo interno y entre modernidad y capitalismo que irrevocablemente conduce a su asociación con el impulso colonial.

A continuación, Ángel Octavio Álvarez examina el ethos reaccionario de la modernidad latinoamericana a través de una aproximación a la dimensión política del estilo literario. En su artículo "Una modernidad «antimoderna». El problema del estilo en Nicolás Gómez Dávila y Octavio Paz", el autor se aproxima al estilo literario, no como una cuestión meramente formal, sino esencialmente política. El artículo tiene como hipótesis de partida la idea de que la modernidad latinoamericana se ve a atravesada por una temporalidad diacrónica donde el tiempo liberal y el reaccionario están en una continua tensión. Para mostrar la especificidad de la formación estético-política latinoamerica y su relación con el estilo "antimoderno", Álvarez analiza, por una parte, el estilo como problema ético en la obra del colombiano Nicolás Gómez Dávila y, por otra parte, la dimensión reaccionaria del estilo de Octavio Paz. Con ello, evidencia cómo se constitución como síntoma de un ethos epocal.

En "Leer demasiado, no leer lo suficiente: relación, ilegibilidad y lo popular en Alejandro Moreno", Carlos Colmenares Gil aborda la cuestión de la especificidad de la espisteme en relación con el sujeto popular venezolano. Para ello, el artículo se centra en la obra de Alejandro Moreno, especialmente en el libro Historia-de-vida de Felicia Valera, donde encuentra el autor encuentra la expresión de los problemas teóricos que surgen al tratar de hacer inteligible la especificidad de las realidades latinoamericanas y, especialmente, la venezolana. Colmenares Gil confronta así al lector con la relación entre la práctica literaria de hacer legibles elementos como actividad lectora con la actividad teorética de conceptualización, que pretende hacer inteligible un objeto. Mediante un despliegue analítico desde esta perspectiva, el artículo muestra el marco de inteligibilidad que impone la modernidad en el mundo y en el pensamiento latinoamericano, así como su influencia en la legibilidad e inteligibilidad de sus realidades.

Pablo López Carballo contribuye a este número con "La emancipación por la literatura. Ideas de lo literario en la Argentina de los setenta: Osvaldo Lamborghini y el grupo Literal", en el que aborda algunas de las transformaciones acontecidas en el ámbito literario argentino a finales del siglo veinte. López Carballo analiza la dimensión emancipadora de la producción cultural del grupo Literal, no solo en relación con su posicionamiento inmediata o directamente político, sino especialmente en las propias reformulaciones que acontecen en las formas representativas y estilísticas del nuevo escenario cultural argentino del siglo XX. Más allá de la merca contextualización sociopolítica, el artículo examina las propuestas artísticas del grupo Literal para mostrar la dimensión emancipadora de la creación literaria del momento. Para ello, López Carballo analiza en profundidad la controvertida obra de Osvaldo Lamborghini, en tanto que uno de sus principales exponentes.

ccatalinag@gmail.com

Universidad Complutense de Madrid 
El siguiente texto, "El alma al trabajo y el trabajo del alma: apuntes para una crítica de la continuidad dictatorial en La aventura de los bustos de Eva de Carlos Gamerro", Matias Beverinotti examina críticamente cómo la actual concepción sacrificial del trabajo, que mina la dimensión anímica del sujeto, es heredera de las prácticas y representaciones propias de la última época dictatorial latinoamericana. Para ello, Beverinotti aborda una obra fundamental en la producción literaria argentita, la novela La aventura de los bustos de Eva, de Carlos Gamerro. A través de ella, el artículo pone de manifiesto cómo las transformaciones neoliberales en el ámbito laboral, que demandan una identidad profesional a expensas del alma del trabajador, encuentran su momento genealógico en la cultura del trabajo del período dictatorial argentino. Este recorrido no solo fundamenta una crítica de la actual disposición laboral hedonista y sacrificial, sino también trata de esbozar una posible superación, planteada como la busca de una cultura que recupere del alma en y del trabajo.

Tatiana Llaguno Nieves contribuye a este número con un artículo en el que explora el problema de la exclusión del cuerpo en el ámbito de la reflexión filosófica, así como su reducción a la feminidad, mostrando el potencial emancipador que expresa el movimiento feminista latinoamericano, en la medida en que pone de nuevo la corporalidad en el centro de su reflexión y de su práctica. "¿Y si fuera el cuerpo quien animase al alma?: política feminista, corporalidad y democracia" argumenta el potencial democratizador y emancipador del feminismo popular, en la medida en que poniendo el cuerpo en el centro y en la base de sus reivindicaciones está en condiciones de señalar críticamente el modo en que el capitalismo, no solo trata de renegar o dominar la corporalidad, sino también produce explotación y expropiación en relación con una previa distinción entre cuerpos. Llaguno ofrece así un recurrido del problema del cuerpo que, comenzando desde una dimensión más teórica, pasa por su especificidad en la dominación capitalista, para acabar sirviendo como punto de intelección del potencial democrático y emancipador del feminismo latinoamericano.
En "El vacío del populismo latinoamericano frente a la ontología política europea", Adrià Porta Caballé analiza con detalle las aportaciones teóricas que Dussel y Laclau realizaron en el ámbito de la ontología. Tras un examen crítico de sus postulados ontológicos -sobre el ser, el no-ser y lo Otro- de la Filosofía de la Liberación, el artículo aborda el modo en que Laclau conceptualiza el problema del vacío. Porta argumenta que esta posición filosófica se presenta como una matriz intelectiva idónea para la comprensión tanto del fenómeno del populismo de manera general, como del populismo latinoamericano particularmente. El artículo ofrece tanto una revisión de algunas de las aportaciones a la ontología filosófica por parte del pensamiento latinoamericano, como un abordaje de la política latinoamericana desde un punto de vista ontológico. La propuesta filosófica y analítica que esboza Porta trata de hacer integrable aquello que la ontología del horror vacui y sus reminiscencias en el pensamiento latinoamericano ha excluido sistemáticamente, elementos tales como lo femenino, lo popular o lo bárbaro.

Finalmente, en número se cierra con un artículo de David Cardozo Santiago, en el que se plantea un interesante recorrido que va desde el análisis del problema de la tierra y del indio en el pensamiento de Mariátegui, pasando por su comparación con las aportaciones realizadas por los populistas rusos en relación con la comuna rural, para finalmente preguntarse por la distancia de ambos posicionamientos emancipadores del marxismo de Marx. El artículo "El pensamiento de José Mariáteguir: ¿entre marxismo y populismo?” examina el lugar que las estructuras comunitarias del ayllu desempeñan en el diagnóstico de la situación concreta peruana que realiza Mariátegui a principios del siglo $\mathrm{XX}$, así como las posibilidades emancipadoras que desde ella se podrían abrir. Las propuestas para abordar la cuestión de la tierra y del indio son contrastadas con las que realizaran los populistas rusos sobre las herencias de la obshina o comuna rural rusa, especialmente por parte de Herzen y Chernyshevski, en la Rusia del siglo XIX. Con todo ello, Cardozo examina cómo y en qué medida estas propuestas se apartan del marxismo atribuido al propio Marx. 